\title{
Spontaneous rupture of abdominal wall after breast reconstruction using deep inferior epigastric perforator flap following mastectomy for breast cancer
}

\author{
Jun Iwabu' ${ }^{1}$, Tsutomu Namikawa ${ }^{1 *}$, Hiroyuki Kitagawa ${ }^{1}$, Kazune Fujisawa ${ }^{1}$, Toyokazu Oki ${ }^{1}$, Maho Ogawa',
} Natsuko Iwai ${ }^{2}$, Akiko Yano ${ }^{2}$, Motone Kuriyama ${ }^{2}$, Takeki Sugimoto ${ }^{1}$ and Kazuhiro Hanazaki ${ }^{1}$

\begin{abstract}
Background: The demand for breast reconstruction after mastectomy is rising. The use of deep inferior epigastric perforator (DIEP) flap in autologous reconstruction is a popular approach. There were some reports about abdominal complications after breast reconstruction. However, there was no report about spontaneous rupture of abdominal wall.

Case presentation: A 46-year-old female patient was diagnosed with left breast cancer. Left mastectomy with sentinel lymph node biopsy was performed, and the breast was reconstructed using DIEP flap simultaneously. She suffered heavy abdominal pain and vomiting at postoperative day 4. Computed tomography showed bowel herniation into the subcutaneous tissue caused by left abdominal wall rupture. The abdominal wall was sutured and repaired using mesh by emergency surgery.

Conclusions: To the best of our knowledge, this is the first case about spontaneous rupture of abdominal wall after breast reconstruction using DIEP flap to be reported in the English literature. DIEP flap on breast reconstructive surgery may cause spontaneous rupture of abdominal wall.
\end{abstract}

Keywords: Spontaneous rupture, Abdominal wall, Breast cancer, Deep inferior epigastric perforator

\section{Background}

The demand for breast reconstruction after mastectomy is rising. Despite increasing implant-based reconstruction, the autologous reconstruction is still popular $[1,2]$. Especially, the deep inferior epigastric perforator (DIEP) flaps in breast reconstruction has been most popular method in recent years [3, 4]. Previous reports showed that DIEP flaps technique induced abdominal complications such as delayed wound healing and seroma [5-7]. However, little is known about emergency abdominal complication that required surgical intervention after breast reconstruction. Herein, we report the spontaneous rupture of abdominal wall after breast reconstruction using DIEP flaps, which is considered very rare.

\footnotetext{
* Correspondence: tsutomun@kochi-u.ac.jp

${ }^{1}$ Department of Surgery, Kochi Medical School, Nankoku, Kochi 783-8505,

Japan

Full list of author information is available at the end of the article
}

\section{Case presentation}

A 46-year-old Japanese female patient was referred to Kochi Medical School Hospital for the treatment of left breast cancer. Her height, body weight, and body mass index (BMI) were $151.2 \mathrm{~cm}, 55.0 \mathrm{~kg}$, and 24.1, respectively. She had been experiencing vaginal delivery two times. She did not have any past history regarding abdominal diseases or surgery. Disease stage of left breast cancer was diagnosed as T2NOM0, stage IIA, according to the International Union Against Cancer (UICC) TNM classification, by using mammography, computed tomography (CT), and 18F-fluorodeoxyglucose positron emission tomography (FDG-PET). She underwent left mastectomy with sentinel lymph node biopsy. There was no metastatic lesion in sentinel lymph nodes, and immediate breast construction using left DIEP flap was performed. DIEP flaps were raised in a standard manner which is anastomosed by two perforators located medial of rectus abdominis. 
We made an incision into anterior sheath longitudinally at the center of the muscle. The rectus muscle was split for dissecting the deep inferior the epigastric vessels during flap harvesting. One branch of the intercostal nerve was sacrificed when the inferior epigastric vessels were harvested. The linea alba of this patient was separated due to two deliveries. She underwent abdominoplasty by suturing the rectus abdominis fascia. The tension of the abdominal wall was not strong after abdominoplasty.

Four days later, she suffered heavy abdominal pain and vomiting after defecation. Abdominal X-ray examination showed niveau imaging (Fig. 1), and CT showed bowel herniation into the subcutaneous space (Fig. 2). Under a clinical diagnose of postoperative herniation caused by spontaneous rupture of the abdominal wall, we performed emergency operation.

Because there was no finding of bowel strangulation, the small intestine was replaced into the abdominal cavity without bowel resection (Fig. 3a). Abdominal wall lateral of the rectus abdominis was ruptured measuring $3 \mathrm{~cm}$ in diameter, which was located at caudal side of arcuate line (Fig. 3b). The ruptured abdominal wall was sutured, covering onlay polypropylene mesh after bowel repositioned into the abdominal cavity (Fig. 3c, d). She got out of hospital without other complication after 11 days later from emergency surgery. After 6 months of following the operation, the patient was asymptomatic and there was no abnormal finding of the donor site (Fig. 4).

\section{Discussion}

Since the first report in 1994 [3], the number of patients underwent DIEP free flap reconstruction was increasing.

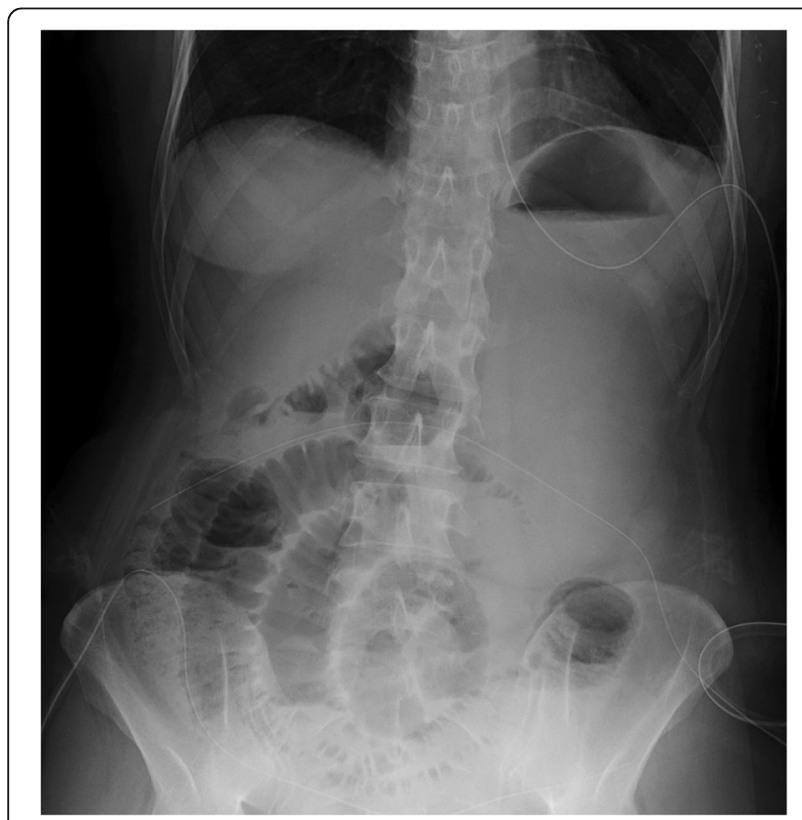

Fig. 1 Abdominal X-ray examination showing niveau sign

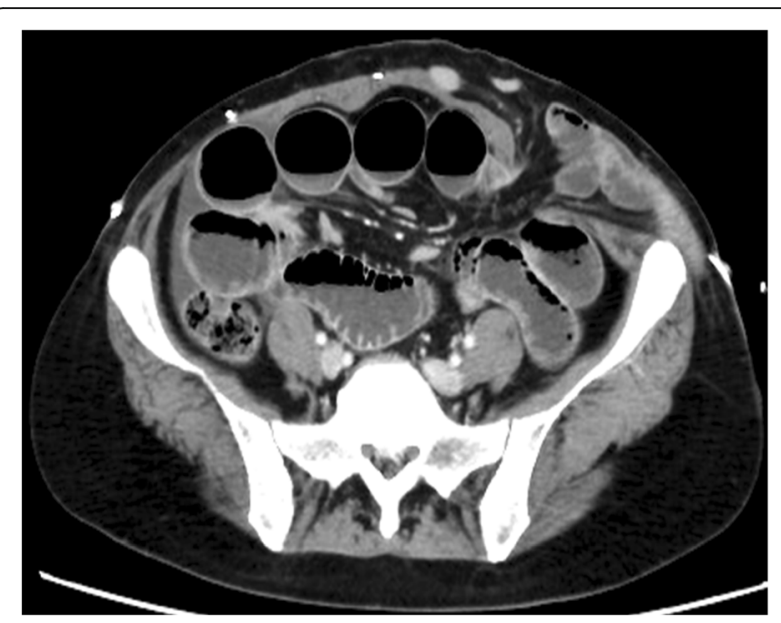

Fig. 2 Abdominal contrast-enhanced computed tomography showing bowel herniation into the subcutaneous tissue

The autologous reconstruction accounts for up to $50 \%$ of total reconstruction until about 2010 in Asia [8, 9]. Recent investigator reported that the reconstruction rate using autologous tissue was decreased to about 20-30\% with the spread of prosthesis-based reconstruction [10]; however, it is still a popular method in autologous reconstruction for breast cancer.

Breast reconstruction using DIEP flap can prevent muscle sacrifice and maintain postoperative rectus abdominis strength and resistance for abdominal pressure. As a result, patients can prevent donor site complications such as bulging and herniation. Despite these advantages of DIEP flap, we experienced that the case of acute spontaneous rupture.

Previous reports showed that the incidence of abdominal complications after autologous reconstruction was ranged from 3.4 to $25.8 \%$. Some reports considered that a higher BMI was associated with higher morbidity in abdominal complications $[5-7,11]$. However, the bulging and herniation of the donor site is rare in previous reports. Recently, the frequency of abdominal herniation after DIEP flap reconstruction is reported $1.8-3.9 \%[12,13]$. There were no any consensus of the risk factor, prevention, and treatment for the bulging and herniation. The mechanism of bulging and herniation is thought to be due to muscle denervation or fascial attenuation by surgical trauma [14]. Another mechanism is assumed that the weakness of the abdominal wall is caused by repeated pregnancy, previous abdominal surgery and obesity, or the increased intra-abdominal pressure [15].

Spontaneous rupture of abdomen in the adult age is also very rare [16-23]. In the previous reports, all cases were occurred following abdominal hernia. Many of these cases were repaired by prolene mesh. In our knowledge, there were no reports about acute abdominal rupture after breast reconstruction without our case. 

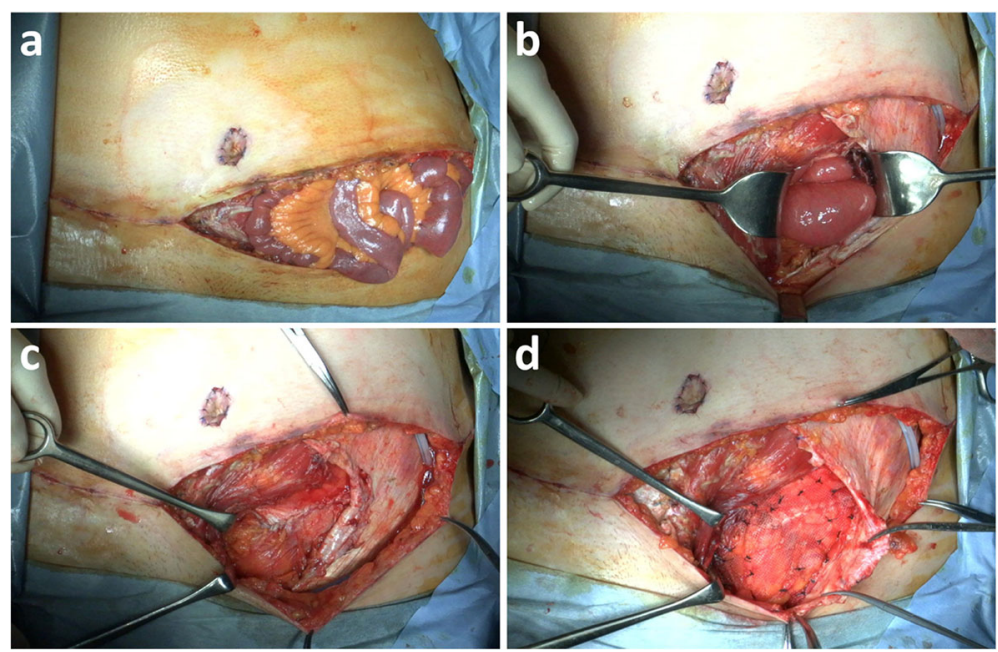

Fig. 3 Intraoperating findings showing abdominal rupture. a Bowel herniation without strangulation. b Abdominal wall rupture measuring 3 cm. c Sutured abdominal wall. d Repaired abdominal wall using onlay mesh

One of reasons for abdominal wall rupture in our case was considered the unconscious injury of peritoneum when inferior epigastric vessels were harvested. In the present case, the rupture area was located at caudal side of arcuate line. The bowel herniation occurred from peritoneum to subcutaneous area through lateral of rectus abdominis and anterior sheath, in which the location did not match the course of pedicle dissection. This rupture seems to be not iatrogenic but spontaneous because the perforator located medial of the rectus abdominis and the rupture occurred through lateral of the muscle. It was not completely denied that this case was iatrogenic; however, we raised DIEP flaps in a standard manner, and we could not perform irregular procedure without abdominoplasty.

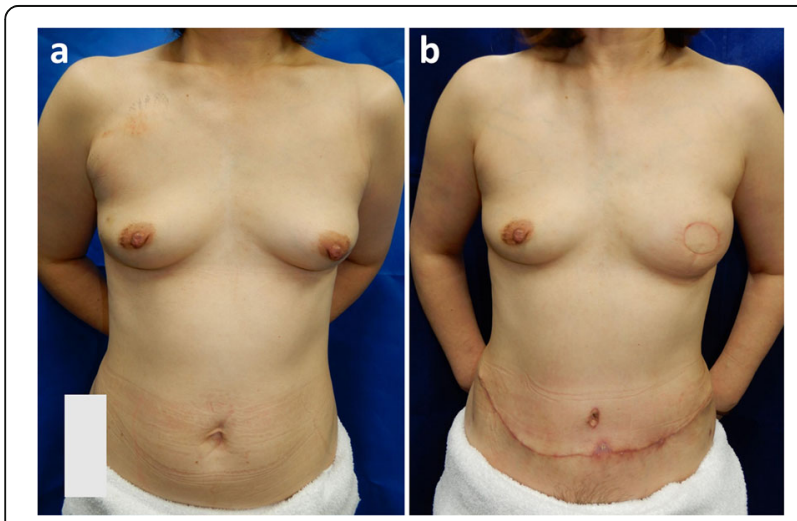

Fig. 4 Pre- and postoperative findings of donor and recipient site. a Appearances prior to mastectomy and DIEP flap reconstruction. $\mathbf{b}$ Post mesh repair of the rupture. There was no abnormal finding of the donor site
The other possibility was the weakness of abdominal wall caused by two transvaginal deliveries. Although she underwent abdominoplasty due to separated linea alba, abdominal wall rupture occurred. The last possibility was that the resistance of the abdominal pressure could not be maintained by sacrificed intercostal nerve. Spontaneous rupture in our case is considered the complex of these elements.

This patient had no obesity (BMI 24.2), and there were no surgical risks other than separated linea alba due to two deliveries. Patients who are expected to have weak fascia of rectus abnomitis, such as separated linea alba and repeated pregnancy, may be recommended mesh reinforcement to prevent postoperative herniation and rupture after DIEP flap reconstruction. A recent study reported the reinforcement of rectus abnomitis with onlay mesh reduce the risk of postoperative bulge after DIEP reconstruction [24]. Onlay mesh reinforcement may have a disadvantage such as infection. The other study which evaluated the prevention of incisional hernia in midline laparotomies reported that a significant reduction in incidence of incisional hernia was achieved with onlay mesh reinforcement group with sublay mesh group and primary suture group [25]. In addition, they showed that the incidence of wound infection did not differ between the three groups. So, the disadvantage of infection using onlay mesh may be acceptable.

Of course, patients who choose autologous reconstruction tend to avoid implant. Furthermore, it is essential to inform the risk and benefit of mesh reinforcement. To avoid severe postoperative complication for high-risk patients, we think that mesh reinforcement is acceptable. Although abdominal rupture after breast reconstruction using DIEP is considered very rare, it might be safe to apply 
onlay mesh on the abdominal wall for reinforcement after breast reconstruction using DIEP flap in case of the patients such as separated linea alba and repeated pregnancy.

\section{Conclusions}

This is the first report about spontaneous rupture of abdominal wall after breast reconstruction using DIEP flap. The treatment procedure of this complication might be considered as a repair using onlay mesh in addition to primary suture.

\section{Abbreviations}

$\mathrm{CT}$ : Computed tomography; DIEP: Deep inferior epigastric perforator

\section{Authors' contributions}

$\mathrm{J}$ and $\mathrm{TN}$ contributed to the writing of the manuscript. MK and $\mathrm{KH}$ supervised the study. JI, HK, KF, TO, MO, NI, AY, MK, and TS served as the attending physicians of the presented patient. All authors read and approved the final manuscript.

\section{Ethics approval and consent to participate}

This study was carried out in accordance with the principal of the Declaration of Helsinki.

\section{Consent for publication}

The patient has given consent for the publication of images.

\section{Competing interests}

The authors declare that they have no competing interests.

\section{Publisher's Note}

Springer Nature remains neutral with regard to jurisdictional claims in published maps and institutional affiliations.

\section{Author details}

${ }^{1}$ Department of Surgery, Kochi Medical School, Nankoku, Kochi 783-8505, Japan. ${ }^{2}$ Department of Plastic and Reconstructive Surgery, Kochi Medical School, Nankoku, Kochi, Japan.

Received: 23 March 2018 Accepted: 23 July 2018

Published online: 31 July 2018

\section{References}

1. Jagsi R, Jiang J, Momoh AO, Alderman A, Giordano SH, Buchholz TA Kronowitz SJ, Smith BD. Trends and validation in use of breast reconstruction in patients with breast cancer undergoing mastectomy in the United States. J Clin Oncol. 2014;32:919-26.

2. Farhangkhoee $\mathrm{H}$, Matros $\mathrm{E}$, Disa J. Trends and concepts in post-mastectomy breast reconstruction. J Surg Oncol. 2016;113:891-4.

3. Allen RJ, Treece P. Deep inferior epigastric perforator flap for breast reconstruction. Ann Plast Surg. 1994;32:32-8.

4. Healy C, Allen RJ Sr. The evolution of perforator flap breast reconstruction: twenty years after the first DIEP flap. J Reconstr Microsurg. 2014;30:121-5.

5. Fischer JP, Nelson JA, Kovach SJ, Serletti JM, Wu LC, Kanchwala S. Impact of obesity on outcomes in breast reconstruction: analysis of 15,937 patients from the ACS-NSQIP datasets. J Am Coll Surg. 2013;217:656-64.

6. Hanwright PJ, Davila AA, Hirsch EM, Khan SA, Fine NA, Bilimoria KY, Kim JY. The differential effect of $\mathrm{BMI}$ on prosthetic versus autogenous breast reconstruction: a multivariate analysis of 12,986 patients. Breast. 2013;22: 938-45.

7. Garvey PB, Buchel EW, Pockaj BA, Gray RJ, Samson TD. The deep inferior epigastric perforator flap for breast reconstruction in overweight and obese patients. Plast Reconstr Surg. 2005;115:447-57.

8. Kim Z, Min SY, Yoon CS, Lee HJ, Lee JS, Youn HJ, Park HK, Noh DY, Hur MH, Society KBC. The basic facts of Korean breast cancer in 2011: results of a nationwide survey and breast cancer registry database. J Breast Cancer. 2014;17:99-106
9. Oda A, Kuwabara H, Fushimi K. Disparities associated with breast reconstruction in Japan. Plast Reconstr Surg. 2013;132:1392-9.

10. Hong KY, Son Y, Cang H, Jin US. Trends in breast reconstruction: implications for the National Health Insurance Service. Arch Plast Surg. 2018:45:239-45.

11. Paik JM, Lee KT, Jeon BJ, Lim SY, Pyon JK, Bang SI, Oh KS, Mun GH. Donor site morbidity following DIEP flap for breast reconstruction in Asian patients: is it different? Microsurgery. 2015;35:596-602.

12. Shubinets V, Fox JP, Sarik JR, Kovach SJ, Fischer JP. Surgically treated hernia following abdominally based autologous breast reconstruction: prevalence, outcomes, and expenditures. Plast Reconstr Surg. 2016;137:749-57.

13. Jeong $\mathbf{W}$, Lee $\mathbf{S}$, Kim J. Meta-analysis of flap perfusion and donor site complications for breast reconstruction using pedicled versus free TRAM and DIEP flaps. Breast. 2018:38:45-51.

14. Nahabedian MY. Secondary operations of the anterior abdominal wall following microvascular breast reconstruction with the TRAM and DIEP flaps. Plast Reconstr Surg. 2007;120:365-72.

15. Conroy K, Malata CM. Epigastric hernia following DIEP flap breast reconstruction: complication or coincidence? J Plast Reconstr Aesthet Surg. 2012;65:387-91.

16. Hartely RC. Spontaneous rupture of incisional hernia. Br J Surg. 1962;49:617-8.

17. Hamilton RW. Spontaneous rupture of incisional hernia. Br J Surg. 1966;53: 477-9.

18. Agarwal PK. Spontaneous rupture of incisional hernia. Br J Clin Pract. 1986; 40:443-4.

19. Singla SL, Kalra U, Singh B, Narula S, Dahiya P. Ruptured incisional hernia. Trop Dr. 1997;27:112-3.

20. Ogundiran TO, Ayantunde AA, Akute OO. Spontaneous rupture of incisional hernia--a case report. West Afr J Med. 2001;20:176-8.

21. Sagar J, Sagar B, Shah DK. Spontaneous rupture of incisional hernia. Indian J Surg. 2005;67:280-28.

22. Gupta RK, Sah S, Agrawal SC. Spontaneous rupture of incisional hernia: a rare cause of a life-threatening complication. BMJ case reports. 2011; https://doi.org/10.1136/bcr.11.2010.3486.

23. Martis JJ, Shridhar KM, Rajeshwara KV, Janardhanan D, Jairaj D. Spontaneous rupture of incisional hernia--a case report. Indian J Surg. 2011;73:68-70.

24. Wormer BA, Clavin NW, Lefaivre JF, Korn JM, Teng E, Aukskalnis AS, Robinson JM. Reducing postoperative abdominal bulge following deep inferior epigastric perforator flap breast reconstruction with onlay monofilament poly-4-hydroxybutyrate biosynthetic mesh. J Reconstr Microsurg. 2017;33:8-18.

25. Jairam AP, Timmermans L, Eker HH, REGJM P, van Klaveren D, Steyerberg EW, Timman R, van der Ham AC, Dawson I, Charbon JA, Schuhmacher C, Mihaljevic A, Izbicki JR, Fikatas P, Knebel P, Fortelny RH, Kleinrensink GJ, Lange JF, Jeekel HJ, PRIMA Trialist Group. Prevention of incisional hernia with prophylactic onlay and sublay mesh reinforcement versus primary suture only in midline laparotomies (PRIMA): 2-year follow-up of a multicenter, double-blind, randomized controlled trial. Lancet. 2017:390:567-76.

\section{Submit your manuscript to a SpringerOpen ${ }^{\circ}$ journal and benefit from:}

- Convenient online submission

- Rigorous peer review

- Open access: articles freely available online

High visibility within the field

- Retaining the copyright to your article

Submit your next manuscript at $>$ springeropen.com 